\title{
CEGAH COMPUTER VISION SYNDROME SELAMA PEMBELAJARAN DARING PADA MAHASISWA KEDOKTERAN
}

\author{
Nurfitri Bustamam ${ }^{1} *$, Pritha Maya Savitri ${ }^{2}$, Heri Wibisono ${ }^{3}$ \\ ${ }^{1}$ Laboratorium Fisiologi, Fakultas Kedokteran Universitas Pembangunan Nasional Veteran Jakarta, \\ ${ }^{2}$ Laboratorium Ilmu Kesehatan Matra, Fakultas Kedokteran Universitas Pembangunan Nasional Veteran \\ Jakarta, ${ }^{3}$ Prodi Fisioterapi, Fakultas Ilmu Kesehatan, Universitas Pembangunan Nasional Veteran Jakarta \\ *nurfitri.bustamam@upnvj.ac.id
}

\begin{abstract}
During the COVID-19 pandemic, student learning activities are carried out online. Online learning increases the risk of vision symptoms known as computer vision syndrome (CVS). These visual symptoms may also be accompanied by headaches, shoulder pain, or neck pain. Community service activities were carried out to medical students of Universitas Pembangunan Nasional Veteran Jakarta. The activities aimed to increase students' knowledge so that students can make efforts to prevent CVS. Students were asked to fill out a pretest questionnaire to measure knowledge, student behavior related to computer use, and identify CVS problems. After filling out the pre-test, they were given education via zoom meeting about CVS and its preventive efforts using slides and videos. Furthermore, students were asked to fill out a post-test questionnaire to measure their knowledge. Two weeks later, another zoom meeting was held to measure CVS problems and CVS prevention efforts carried out by the students. The activities result showed that the level of students' knowledge increased. After two weeks of implementing the preventive efforts, the number of students experiencing CVS decreased. It can be concluded these community service activities have succeeded in overcoming the CVS experienced by the students during online learning.
\end{abstract}

Keywords: computer vision syndrome; education; online learning; medical students

\begin{abstract}
Abstrak
Pada pandemi COVID-19, kegiatan pembelajaran mahasiswa dilakukan secara daring. Pembelajaran daring meningkatkan risiko timbulnya sejumlah gejala penglihatan yang dikenal dengan computer vision syndrome (CVS). Gejala penglihatan tersebut dapat pula disertai nyeri kepala, nyeri bahu, atau nyeri leher. Kegiatan PKM dilakukan kepada mahasiswa kedokteran Universitas Pembangunan Nasional Veteran Jakarta dengan tujuan meningkatkan pengetahuan mahasiswa sehingga mahasiswa dapat melakukan upaya untuk mencegah CVS. Mahasiswa diminta mengisi kuesioner pre-test untuk mengukur pengetahuan, perilaku terkait penggunaan komputer, dan mengidentifikasi masalah CVS. Setelah mengisi pre-test, mahasiswa diberi edukasi tentang CVS dan upaya pencegahannya melalui zoom meeting menggunakan slide dan video. Selanjutnya mahasiswa diminta mengisi kuesioner post-test untuk mengukur tingkat pengetahuannya. Dua minggu kemudian diadakan kembali zoom meeting untuk mengukur masalah CVS dan implementasi upaya pencegahan CVS yang dilakukan mahasiswa. Hasil PKM menunjukkan tingkat pengetahuan mahasiswa meningkat. Setelah dua minggu mengimplementasikan upaya pencegahan, jumlah mahasiswa yang mengalami CVS berkurang. Dapat disimpulkan kegiatan PKM berhasil mengatasi CVS yang dialami mahasiswa selama pembelajaran daring.
\end{abstract}

Kata Kunci: computer vision syndrome; edukasi; mahasiswa; pembelajaran daring

\begin{tabular}{l|l|l} 
Submitted: $2021-07-22$ & Revised: $2021-10-26$ & Accepted: 2021-10-28
\end{tabular}

\section{Pendahuluan}

Pada pandemi COVID-19, kegiatan pembelajaran mahasiswa dilakukan secara daring. Pembelajaran daring meningkatkan risiko timbulnya computer vision syndrome (CVS) yaitu kumpulan gejala pada mata dan penglihatan yang berhubungan dengan aktivitas penglihatan jarak dekat dan berlangsung selama atau setelah menggunakan perangkat digital misalnya komputer atau telpon pintar (AOA, 2019). Secara umum, gejala CVS dapat dikelompokan menjadi tiga, yaitu: 1) gejala yang berkaitan dengan ocular (mata kering, mata berair, iritasi mata, dan sensasi mata terbakar); 2) gejala penglihatan (mata tegang, mata lelah, nyeri kepala, penglihatan kabur, dan penglihatan ganda); dan 3) gejala ekstraokular (nyeri leher, nyeri bahu, dan nyeri punggung) (Munshi, Varghese \& Dhar-Munshi, 2017).

Prevalensi CVS diperkirakan 75-90\% dari pengguna komputer (Ranasinghe et al., 2016). Di Nepal didapatkan prevalensi CVS sebesar 71,6\% pada mahasiswa kedokteran (Kharel \& Khatri, 
2018). Hasil wawancara pengabdi dengan beberapa mahasiswa Fakultas Kedokteran Universitas Pembangunan Nasional Veteran Jakarta (FK UPNVJ) didapatkan mahasiswa tersebut juga mengalami gejala CVS selama pembelajaran daring. Mahasiswa FK UPNVJ pada umumnya menggunakan laptop selama pembelajaran daring yang dijadwalkan fakultas 5-6 jam/hari mulai hari Senin sampai Jum'at. Pembelajaran daring terkadang dilakukan mahasiswa di dalam ruang yang intensitas cahayanya kurang atau tidak menggunakan meja dan kursi yang sesuai sehingga posisi tubuh menjadi tidak ergonomis. Hal tersebut merupakan beberapa faktor yang berkontribusi terhadap timbulnya CVS (Gowrisankaran \& Sheedy, 2015).

Pembelajaran pada mahasiswa yang mengalami CVS akan kurang optimal, sehingga dapat menurunkan hasil belajar. Sesungguhnya gejala CVS bersifat temporer atau hilang setelah berhenti menggunakan komputer/perangkat digital. Namun, jika tidak ada upaya pencegahan, gejala CVS akan berlanjut dan semakin berat (AOA, 2019). Berdasarkan masalah tersebut, tim pengabdi memandang perlu untuk bekerjasama dengan Badan Eksekutif Mahasiswa FK UPNVJ melakukan kegiatan pengabdian kepada masyarakat (PKM). Kegiatan PKM ini bertujuan untuk meningkatkan pengetahuan mahasiswa sehingga mahasiswa dapat melakukan upaya untuk mencegah CVS.

\section{Metode}

Pada kegiatan PKM ini yang menjadi mitra adalah mahasiswa FK UPNVJ tahun pertama (Angkatan 2020). Pengabdi berkoordinasi dengan Badan Eksekutif Mahasiswa dan ketua Angkatan FK UPNVJ 2020 untuk menyebarluaskan flyer kegiatan PKM dan tautan (link) kesediaan mahasiswa sebagai mitra untuk mengikuti rangkaian kegiatan PKM. Kegiatan PKM dilaksanakan pada tanggal 3-18 Juni 2021 secara daring.

Tim pengabdi datang ke Perpustakaan FK UPNVJ yang terletak di Jl. RS Fatmawati, Pondok Labu pada hari pada hari Kamis, 3 Juni 2021 pukul 15.00 WIB untuk melakukan persiapan. Kegiatan PKM dilakukan pukul 15.30-17.30 WIB melalui zoom meeting. Kegiatan diawali dengan pembukaan untuk menjelaskan rangkaian kegiatan dan hasil yang diharapkan melalui PKM. Selanjutnya mitra diminta mengisi google form (pre-test) untuk mengukur tingkat pengetahuan, mendapatkan gambaran perilaku mahasiswa terkait penggunaan komputer, dan mengidentifikasi masalah CVS menggunakan kuesioner yang valid (Seguí et al., 2015).

Setelah mengisi pre-test, mitra diberi edukasi tentang CVS dan upaya pencegahannya menggunakan slide dan video. Pengabdi pertama dengan latar belakang pengetahuan fisiologi memberikan materi tentang: 1) Computer vision syndrome mencakup definisi, gejala, etiologi, faktor yang berkontribusi, diagnosis dan upaya preventif yang dapat dilakukan, serta 2) Edukasi tentang bagaimana menggunakan komputer agar tidak mengalami CVS. Pengabdi kedua dengan latar belakang pendidikan fisioterapi menjelaskan dan mendemostrasikan postur tubuh yang benar pada saat menggunakan komputer dan latihan peregangan yang mudah dilakukan mitra untuk menurunkan ketegangan otot, menghilangkan nyeri leher, bahu, dan punggung. Acara dilanjutkan dengan sesi diskusi dan diakhiri dengan memberikan nasihat agar mitra mengimplementasikan upaya pencegahan CVS (Gambar 1).

Setelah pengabdi mendapatkan data mitra berkaitan dengan masalah CVS, pengabdi mengirimkan email kepada setiap mitra disertai leaflet yang berisi cara mencegah CVS. Kepada mitra yang mengalami CVS, pengabdi memotivasi agar mitra melakukan upaya pencegahan CVS sehingga gejala CVS tidak berlanjut dan semakin parah. Kepada mitra yang tidak mengalami CVS, pengabdi mengingatkan untuk tetap melakukan upaya pencegahan CVS agar tetap sehat selama pembelajaran daring.

Dua minggu kemudian diadakan kembali zoom meeting. Pengabdi menyampaikan hasil analisis data yang didapatkan pada tanggal 3 Juni 2021, antara lain permasalah CVS yang dialami mitra, perilaku mitra yang salah dalam menggunakan komputer, dan peningkatan pengetahuan mitra tentang CVS setelah mengikuti edukasi. Selanjutnya mitra diminta mengisi google form untuk 
mengukur implementasi upaya pencegahan CVS dalam dua minggu terakhir dan manfaatnya menggunakan kuesioner CVS. Acara dilanjutkan dengan diskusi dan pemberian umpan balik oleh mitra tentang kegiatan PKM.

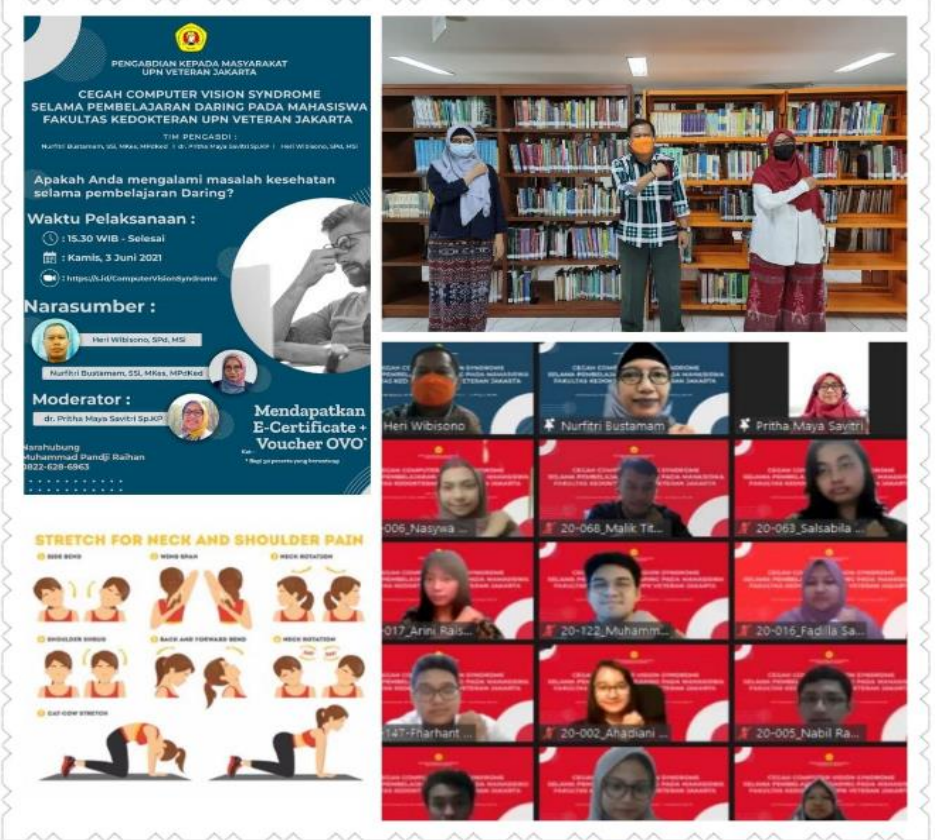

Gambar 1. Kegiatan PKM secara daring, flyer PKM, dan tim pengabdi

Evaluasi hasil kegiatan PKM dilakukan oleh pengabdi dengan cara membandingkan data sebelum dan setelah intervensi. Data yang dievaluasi adalah pengetahuan, perilaku, dan masalah CVS mitra.

\section{Hasil dan Pembahasan}

Kegiatan PKM diikuti oleh 85 peserta termasuk mahasiswa dan dosen. Yang bersedia menjadi mitra PKM dan mengikuti seluruh rangkaian kegiatan PKM ada 38 mahasiswa. Berdasarkan karakteristik demografinya, sebagian besar (28 orang) mitra adalah perempuan dengan usia 18 (17-20) tahun.

Mitra menggunakan komputer dalam sehari selama 10 (6-17) jam, khusus untuk pembelajaran mitra menggunakannya selama 7 (5-10) jam. Selain untuk pembelajaran, komputer juga digunakan oleh mitra untuk aktivitas sosial media, nonton film, dan main games. Pada umumnya mitra (34 orang) memilih menggunakan laptop untuk pembelajaran daring. Sebagian besar mitra ( 25 orang) berkacamata minus dengan rincian 14 orang dengan myopia ringan dan 11 orang dengan myopia sedang. Sebanyak 13 orang mitra juga mengaku menggunakan lensa silindris (mata astigmat). Penggunaan komputer dalam jangka lama ( $>2$ jam) dan adanya kelainan refraksi pada mitra merupakan faktor yang berkontribusi terhadap timbulnya CVS. Mitra tersebut diingatkan untuk menggunakan kacamata yang sesuai dan memeriksakan penglihatannya ke dokter 1-2 tahun sekali sebagai upaya preventif mencegah CVS (AOA, 2019).

Pada PKM ini didapatkan data 27 dari 38 (71\%) mitra mengalami CVS, bahkan ada yang disertai dengan nyeri leher, bahu, dan punggung. Sejumlah perilaku mitra yang salah juga diketahui dalam PKM ini, yaitu menggunakan komputer lebih dari dua jam tanpa berhenti, tidak mengimplementasikan rule 20-20-20 (mengistirahatkan mata selama 20 detik dengan memandang benda yang letaknya jauh ( $>20$ feet) setiap 20 menit, tidak mengedipkan mata dengan sengaja untuk mencegah mata kering, tidak menggunakan fasilitas meja dan kursi yang sesuai sehingga postur mitra salah (janggal) saat menggunakan komputer, dan tidak melakukan latihan 
peregangan. Perilaku tersebut erat kaitannya dengan masalah CVS (Akinbinu \& Mashalla, 2014) dan nyeri muskuloskelatal yang dialami mitra (Logaraj et al., 2013). Oleh karenanya, pengabdi merasa perlu memberikan edukasi tentang CVS kepada mitra.

Sebelum dan setelah edukasi, mitra diminta untuk mengisi kuesioner berkaitan dengan materi penyuluhan untuk mengetahui tingkat pengetahuan. Berdasarkan hasil analisis didapatkan ada peningkatan skor pengetahuan dari 4 (2-6) menjadi 7 (5-8). Hasil uji Wilcoxon menunjukkan skor pengetahuan pada 29 mitra meningkat, 6 mitra tetap dan 3 mitra menurun dibandingkan dengan skor pengetahuan sebelum edukasi $(p=0,000)$. Hal tersebut menunjukkan bahwa informasi yang disampaikan dalam edukasi dapat dipahami mitra. Peningkatan pengetahuan ini diharapkan dapat memotivasi mitra khususnya yang mengalami CVS untuk melakukan perubahan perilaku sebagai upaya mencegah CVS.

Hasil Marginal Homogeinity Test menunjukkan mitra telah melakukan upaya pencegahan CVS secara signifikan $(p \leq 0,05)$ selama dua minggu setelah edukasi. Upaya yang dilakukan adalah duduk dengan postur ergonomis pada saat menggunakan komputer, jarak monitor ke mata kirakira $60 \mathrm{~cm}$ (2 feet), komputer diletakkan lebih rendah dari posisi horizontal mata, mengimplementasikan 20-20-20 rule, beristirahat 15 menit setiap 2 jam menggunakan komputer dan melakukan latihan peregangan. Namun, ada beberapa perilaku yang belum dilakukan mitra secara signifikan $(p>0,05)$ untuk mencegah CVS, yaitu sengaja berkedip pada saat menggunakan komputer, menggunakan kursi yang ergonomis, dan mengatur cahaya monitor dan ruang cukup terang pada saat belajar daring (Tabel 1 ).

Tabel 1. Upaya mitra mencegah CVS sebelum (pre) dan setelah (post) PKM

\begin{tabular}{|c|c|c|c|c|c|c|c|c|}
\hline \multirow{2}{*}{ No. } & \multirow{2}{*}{ Upaya Pencegahan } & \multicolumn{2}{|c|}{ Tidak Pernah } & \multicolumn{2}{|c|}{ Kadang-Kadang } & \multicolumn{2}{|c|}{ Seringkali } & \multirow{2}{*}{$\mathrm{p}$} \\
\hline & & Pre & Post & Pre & Post & Pre & Post & \\
\hline 1. & Postur ergonomis & 2 & 0 & 26 & 18 & 10 & 20 & 0,019 \\
\hline 2. & Jarak monitor $60 \mathrm{~cm}$ & 5 & 1 & 24 & 13 & 9 & 24 & 0,001 \\
\hline 3. & Letak monitor lebih rendah & 8 & 0 & 17 & 18 & 13 & 20 & 0,005 \\
\hline 4. & $\begin{array}{l}\text { Mengimplementasikan rule } \\
20-20-20\end{array}$ & 15 & 2 & 22 & 24 & 1 & 12 & 0,000 \\
\hline 5. & $\begin{array}{l}\text { Berhenti } 15 \text { menit setiap } 2 \\
\text { jam }\end{array}$ & 6 & 1 & 26 & 17 & 6 & 20 & 0,001 \\
\hline 6. & $\begin{array}{l}\text { Melakukan latihan } \\
\text { peregangan }\end{array}$ & 9 & 3 & 24 & 19 & 5 & 16 & 0,002 \\
\hline 7. & Sengaja berkedip & 3 & 2 & 22 & 23 & 13 & 13 & 0,827 \\
\hline 8. & $\begin{array}{l}\text { Menggunakan kursi yang } \\
\text { ergonomis }\end{array}$ & 8 & 4 & 15 & 15 & 15 & 19 & 0,088 \\
\hline 9. & $\begin{array}{l}\text { Mengatur cahaya monitor } \\
\& \text { ruang cukup terang }\end{array}$ & 0 & 1 & 14 & 11 & 24 & 26 & 0,782 \\
\hline
\end{tabular}

Upaya yang dilakukan oleh mitra PKM dirasakan manfaatnya berupa berkurangnya jumlah mitra yang mengalami CVS secara signifikan berdasarkan uji McNemar (Tabel 2).

Tabel 2. Permasalahan CVS pada mitra

\begin{tabular}{|c|c|c|c|c|c|}
\hline & & \multicolumn{2}{|c|}{ Setelah PKM } & \multirow{2}{*}{ Total } & \multirow{2}{*}{$\mathrm{p}$} \\
\hline & & Tidak CVS & CVS & & \\
\hline \multirow{2}{*}{ Sebelum PKM } & Tidak CVS & 8 & 3 & 11 & \multirow{3}{*}{0,003} \\
\hline & CVS & 17 & 10 & 27 & \\
\hline Total & & 25 & 13 & 38 & \\
\hline
\end{tabular}

Analisis skor intensitas dan frekuensi dari gejala CVS mitra berdasarkan uji Wilcoxon didapatkan 28 mitra berkurang, 1 mitra tetap, dan 9 mitra bertambah $(p=0,002)$. Hasil tersebut 
menunjukkan keluhan gejala CVS yang dialami mitra berkurang signifikan. Postur kerja yang salah akan meningkatkan beban kerja sehingga meningkatkan risiko timbulnya keluhan muskuloskeletal. Implementasi ergonomi yang baik pada saat menggunakan komputer menurunkan risiko CVS (Boadi-Kusi et al., 2020).

Implementasi postur yang ergonomis disertai latihan peregangan yang dilakukan mitra juga berhasil menurunkan skor nyeri leher, bahu, dan punggung berdasarkan hasil uji Wilcoxon ( $p<$ 0,05) (Tabel 3). Latihan peregangan terbukti dapat menurunkan keluhan muskuloskeletal pada pekerja di industri Garmen Adhi Fashion (Nooryana, Adiatmika \& Purnawati, 2019).

Tabel 3. Keluhan muskuloskeletal pada mitra setelah mengimplementasikan postur ergonomis dan latihan peregangan selama dua minggu

\begin{tabular}{clcccc}
\hline No. & Keluhan & Berkurang & Tetap & Bertambah & $p$ \\
\hline 1 & Nyeri leher & 16 & 16 & 6 & 0,016 \\
2 & Nyeri bahu & 18 & 16 & 4 & 0,015 \\
3 & Nyeri punggung & 16 & 19 & 3 & 0,002 \\
\hline
\end{tabular}

Sejumlah mitra PKM menyatakan bahwa mereka senang mengikuti kegiatan PKM ini karena merasakan keluhan pada penglihatan dan nyeri di leher dan bahu berkurang setelah mengimplementasikan tips dan latihan yang diberikan selama dua minggu. Mitra lainnya menyebutkan bahwa PKM ini sangat bermanfaat karena sangat sesuai dengan kondisi mahasiswa yang harus belajar daring. Beberapa mitra menghendaki agar materi PKM juga disosialisasikan kepada staf pengajar sehingga staf pengajar dapat memperhatikan durasi penyampaian materinya dan memberi kesempatan pada mahasiswa untuk melakukan peregangan atau mengistirahatkan penglihatan sejenak.

\section{Kesimpulan}

Kegiatan PKM ini berhasil mengatasi masalah CVS yang dialami mahasiswa FK UPNVJ selama pembelajaran daring. Kepada mitra PKM disarankan untuk tetap melakukan upaya pencegahan CVS selama pembelajaran daring serta menyebarluaskan pengalaman/informasi terkait pencegahan CVS ini kepada keluarga, teman atau masyarakat di lingkungannya. Dengan demikian diharapkan permasalahan CVS yang dialami oleh mahasiswa/siswa yang melakukan pembelajaran secara daring dapat dicegah.

\section{Daftar Pustaka}

Akinbinu, T. R. \& Mashalla, Y. J. (2014) 'Medical Practice and Review Impact of computer technology on health: Computer Vision Syndrome ( CVS )', Academic Journals, 5(November), pp. 20-30. doi: 10.5897/MPR.2014.0121.

American Optometric Association. 2019. Computer vision syndrome. Available from: https://www.aoa.org/healthy-eyes/eye-and-vision-conditions/computer-visionsyndrome?sso=y [cited 18 May 2020].

Boadi-Kusi, S. B., Abu, S. L., Acheampong, G. O., Adueming, P. O-W., Abu, E. K. A. (2020) 'Association between Poor Ergophthalmologic Practices and Computer Vision Syndrome among University Administrative Staff in Ghana', Journal of Environmental and Public Health, 2020. doi: $10.1155 / 2020 / 7516357$.

Gowrisankaran, S. \& Sheedy, J. E. (2015) 'Computer vision syndrome: A review', Work, 52(2), pp. 303-314. doi: 10.3233/WOR-152162.

Kharel Sitaula, R. \& Khatri, A. (2018) 'Knowledge, Attitude and practice of Computer Vision Syndrome among medical students and its impact on ocular morbidity', Journal of Nepal 
Health Research Council, 16(3), pp. 291-296. doi: 10.3126/jnhrc.v16i3.21426.

Logaraj, M., Priya, V. M., Seetharaman, N., \& Hedge, S. K. (2013) 'Practice of Ergonomic Principles and Computer Vision Syndrome (CVS) among Undergraduates Students in Chennai', National Journal of Medical Research, 3(2), pp. 111-116. Available at: http://sjournals.net/ojs/index.php/NJMR/article/view/18.

Munshi, S., Varghese, A., \& Dhar-Munshi, S. (2017) 'Computer vision syndrome-A common cause of unexplained visual symptoms in the modern era', International Journal of Clinical Practice, 71(7), pp. 1-5. doi: 10.1111/ijcp.12962.

Nooryana, S., Adiatmika, I. P. G., \& Purnawati, S. (2019) 'Latihan Peregangan Dinamis dan Istirahat Aktif Menurunkan Beban Kerja dan Meningkatkan Produktivitas Pada Pekerja di Industri Garmen Adhi Fashion', Prosiding Seminar Nasional LPPM UMP, pp. 178-184.

Ranasinghe, P., Wathurapatha, W. S., Perera, Y. S., Lamabadusuriya, D. A., Kulatunga, S., Jayawardana, N., et al. (2016) 'Computer vision syndrome among computer office workers in a developing country: An evaluation of prevalence and risk factors', BMC Research Notes. BioMed Central, 9(1), pp. 1-9. doi: 10.1186/s13104-016-1962-1.

Seguí, M. D. M., Cabrero-García, J., Crespo, A., Verdú, J., \& Ronda, E. (2015) 'A reliable and valid questionnaire was developed to measure computer vision syndrome at the workplace', Journal of Clinical Epidemiology. Elsevier Ltd, 68(6), pp. 662-673. doi: 10.1016/j.jclinepi.2015.01.015. 